Gut, 1982, 23, 345-347

\title{
Role of anorectal sensation in preserving continence
}

\author{
MARIA G READ AND N W READ \\ From the Department of Surgery, Royal Hallamshire Hospital, Sheffield
}

SUMMARY The role of anal sensation in preserving continence was studied in nine healthy volunteers. Objective assessment of sphincter function by manometry and rectal saline infusion was carried out during topical anaesthesia of the anal canal using 5\% lignocaine gel and during lubrication with the same amount of inert gel. Anaesthesia successfully abolished anal sensation and reduced both the amplitude and duration of the voluntary squeeze. Basal pressure was unaffected, but the rectal volume required to produce a sustained internal sphincter relaxation was increased. Saline continence was not impaired. Indeed, two subjects, who were previously unable to retain the full $1500 \mathrm{ml}$ of rectally infused saline, did so when the anal canal was anaesthetised. Our findings suggest that anal sensation is not a critical factor in preserving continence. This implies that the incontinence experienced after anorectal surgery or neuropathy cannot be explained by lack of anal sensation alone.

The anal canal is richly supplied with sensory nerve endings, ${ }^{1}$ and the conscious detection and discrimination of solid and liquid faeces and gas by the sensitive anal mucosa ${ }^{2}$ is thought by many to play an essential part in preserving continence. Indeed, the loss of anal sensation has been implicated in the incontinence that can occur after the more radical type of haemorrhoidectomy or fistulectomy, when large areas of anal mucosa are denuded. ${ }^{3}$ We have investigated the role of anal sensation by studying the influence of topical anaesthesia on anorectal function and continence to fluids in normal subjects.

\section{Methods}

\section{SUBJECTS}

The subjects were five female and four male healthy volunteers, aged from 19 to 25 years, who gave no history of anorectal disease or surgery or faecal incontinence. Each subject gave fully informed consent for the study to be carried out. The protocol was approved by the ethical subcommittee of the southern region of the Sheffield Area Health Authority on 5 January 1979.

PROTOCOL

The effect of topical application of gel containing 5\% lignocaine (Biores Laboratories Ltd, London) on anorectal function was compared with the application of an equivalent amount of an inert gel contain-

${ }^{*}$ Received for publication 10 July 1981 ing no anaesthetic (KY jelly, Johnson and Johnson Ltd, Slough). Studies were carried out on separate test days, and the two gels were given in random order. The subjects had no prior knowledge of the nature of the gel used in each study. No bowel preparation was used, apart from offering the subjects the opportunity to have a bowel movement just before the first test. Gel was spread digitally throughout the anal canal at the beginning and at roughly 15-minute intervals throughout the test period, which lasted about 1.5 hours. A total of $15 \mathrm{~g}$ of both the inert and anaesthetic gel was applied.

\section{OBJECTIVE TESTS OF SPHINCTER FUNCTION}

Tests of anal sphincter function were carried out in the following order: (1) measurements of maximum basal and maximum squeeze sphincter pressures by station pull-through technique, using a battery of three open-tipped water-perfused catheters connected to pressure transducers and a chart recorder, (2) measurement of the length of time that the patient could sustain a squeeze pressure of at least $0.6 \mathrm{kPa}$ $\left(6.5 \mathrm{~cm} \mathrm{H} \mathrm{H}_{2} \mathrm{O}\right.$ ) greater than the basal pressure (maximum squeeze duration), (3) measurement of the volume of air in a rectal balloon required to inhibit completely the recovery of the internal sphincter reflex relaxation, (4) measurement of continence to rectal infusion of a total of $1500 \mathrm{ml}$ saline over 25 minutes. The techniques for performing tests (1), (2), and (4) and the reproducibility of these tests have been described. ${ }^{4}$ 
INTERNAL SPHINCTER REFLEX

To elicit the internal sphincter reflex, the recording device was positioned to record the highest basal pressure. The rectal ampulla was then distended by inflating a balloon (situated $7.5 \mathrm{~cm}$ from the recording orifice) with air in increments of $10 \mathrm{ml}$. After the threshold for relaxation was attained, distension of the ampulla always caused a decline in basal sphincter pressure in all subjects tested. This was followed by recovery to the baseline even though the distension was maintained. In all except one subject rectal distension was also associated with a transient increase in anal pressure, which preceded the drop in pressure. This presumably corresponds to the external sphincter response to rectal distension. After recovery of the basal pressure to the original baseline the balloon was deflated and then, after an interval of 30 seconds, reinflated with the previous volume plus $10 \mathrm{ml}$. This procedure was repeated until a volume was reached at which the basal pressure failed to recover during the minute that distension was maintained, and only returned to the baseline when the balloon was deflated. The lowest volume required to inhibit recovery of the internal sphincter reflex was recorded. Values for the lowest pressure attained at the depth of the relaxation were also noted.

This test simulates the situation that occurs when stool enters the rectum. ${ }^{5}$ The resulting rectal distension causes a relaxation in internal sphincter pressure, and at this point the only factor maintaining continence is contraction of the external sphincter, which was thought to be maintained for only $40-60$ seconds. ${ }^{6}$ Thus unless the internal sphincter tone has recovered during this period incontinence is likely to occur. Because of this, the rectal volume required to inhibit recovery of internal sphincter tone for a minute was taken as the most meaningful index in this test.

\section{MEASUREMENT OF ANAL SENSITIVITY}

The sensitivity of the anal canal was determined before and after each of the individual tests of sphincter function. With the subject lying in the left lateral position and the knees drawn up, a probe (external diameter $2 \mathrm{~mm}$ ) consisting of three nylon catheters bonded together so that their distal side openings were $3.5 \mathrm{~cm}$ apart was inserted into the rectum so that the nearest opening was $5 \mathrm{~cm}$ from the anal margin. Two of the catheters were attached to syringes filled with water $\left(37^{\circ} \mathrm{C}\right)$ and one to an air-filled syringe. The probe was slowly withdrawn from the sphincter with the buttocks held widely apart. As each orifice was pulled through the anal canal, the contents of the corresponding syringe were slowly injected. The subject was instructed to say if he could feel (a) the tube at rest in the anal canal, (b) the tube being with- drawn, (c) air bubbling into the anal canal, and (d) the presence of water in the anal canal. Care was taken to disregard the sensation of water once this was seen to be in contact with the perianal skin.

\section{EXPRESSION OF DATA}

Except where indicated, results are expressed as the mean, plus or minus the standard error of the mean of nine subjects. The degrees of significance between the results obtained with the inert and anaesthetic gels were determined by application of Student's paired $t$ test.

\section{Results}

\section{EFFECTS OF LOCAL ANAESTHESIA}

Topical application of 5\% lignocaine gel successfully abolished sensation in all nine subjects. After application of KY jelly all subjects were able to feel the tube moving and all except two could differentiate between air and water. After application of 5\% lignocaine gel, none of the subjects could differentiate between air or water or sense the presence of the tube. Anaesthesia was maintained for the total period of testing.

\section{TEST OF SALINE CONTINENCE}

Topical anaesthesia did not impair continence to rectally infused saline. After application of KY jelly, all but two subjects could retain $1500 \mathrm{ml}$ of rectally infused saline without leakage. After application of anaesthetic gel, these two subjects became continent of the full amount of $1500 \mathrm{ml}$.

\section{ANAL SPHINCTER MANOMETRY (Table)}

Anaesthesia of the anal canal did not influence maximum basal sphincter pressure, but it significantly reduced maximum squeeze pressure.

Squeeze duration was significantly shorter in all subjects when the anal canal was anaesthetised.

Table Analsphincter manometry before and after application of anaesthetic gel in nine normal volunteers

\begin{tabular}{lccc}
\hline & Control & $5 \%$ Lignocaine & $\mathrm{P}$ \\
\hline $\begin{array}{l}\text { Basal spincter } \\
\text { pressure (kPa) }\end{array}$ & $9.4 \pm 0.7$ & $9.2 \pm 0.5$ & $>0.05$ \\
$\begin{array}{c}\text { Squeeze pressure } \\
(\mathrm{kPa})\end{array}$ & $21.0 \pm 2.0$ & $18.6 \pm 1.6$ & $<0.001$ \\
$\begin{array}{c}\text { Internal sphincter } \\
\text { reflex (vol at which } \\
\text { recovery inhibited) } \\
(\text { ml) }\end{array}$ & $108 \pm 17$ & $128 \pm 19$ & $<0.025$ \\
$\begin{array}{c}\text { Squeeze duration } \\
\text { (min) }\end{array}$ & $3.2 \pm 0.6$ & $1.8 \pm 0.3$ & $<0.02$ \\
\hline
\end{tabular}

Results are expressed as mean \pm SEM. Conversion factor for converting $\mathrm{cm} \mathrm{H}_{2} \mathrm{O}$ to $\mathrm{kPa}=10 \cdot 2$. 
After application of anaesthetic gel, a greater volume was required to abolish recovery of the internal sphincter reflex relaxation in all but one subject. There was no significant difference in the threshold volume required to produce a relaxation or in the lowest pressure attained. Reflex external sphincter contraction in response to rectal distension was present in eight of the nine subjects after application of $\mathrm{KY}$ jelly but disappeared in four after application of anaesthetic gel.

\section{Discussion}

Topical application of 5\% lignocaine gel is an effective means of abolishing the sensory discrimination of gases and solids and the ability to detect the movement of a solid object within the anal canal. Thus if anal sensation played an essential part in maintaining continence we should expect this treatment to result in incontinence. As it was unacceptable to determine continence to faeces in these experiments we tested continence to liquids objectively by assessing the response to rectal infusion of a large volume of saline. We had previously observed that the result of this test in patients with diarrhoea was closely related to the incidence of faecal incontinence. ${ }^{4}$

Absence of anal sensation did not impair continence to rectally infused saline in any subject tested and thus would not appear to be an important cause of faecal incontinence. Nevertheless, it was associated with significant reductions in both the strength and duration of external sphincter contraction. The mechanism for these changes in sphincter pressure is uncertain, but they suggest that either voluntary sphincter contraction is dependent in part on sensory input from the anal canal or the anaesthetic had rapidly penetrated into the striated muscle, where it directly inhibited muscle contraction. The other manometric finding was that a greater distending volume was required to inhibit internal sphincter tone completely. Thus although the external sphincter is potentially less effective after anaesthesia, it would seem to be better protected by the internal sphincter and may not be called on to exert a sustained strong contraction. This may explain the improvement in continence that occurred in two subjects after application of local anaesthetic gel.

The receptors for the rectoanal inhibitory reflex are thought to lie in the musculature of the rectal wall ${ }^{7}$ and the pelvic floor ${ }^{8}$ The fact that the sensitivity of the reflex is impaired after topical anaesthesia suggests either that part of the receptor field may lie within the anorectal epithelium or that the anaesthetic had penetrated into the smooth muscle.

If, as our findings suggest, normal anal sensation is not essential for maintaining faecal continence, its major role may be to discriminate between flatus and faeces, and hence may act to indicate the necessity for defecation or signal the end of defecation.

\section{References}

1 Duthie HL, Gairns FW. Sensory nerve endings and sensation in the anal region of man. Br J Surg 1960; 67:585-95.

2 Duthie HL, Bennet RC. The relation of sensation in the anal canal to the functional anal sphincter: a possible factor in anal continence. Gut 1963; 4:179-82.

3 Bennet RC, Friedman MHW, Goligher JC. Late results of haemorroidectomy by ligature and excision. $\mathrm{Br} \mathrm{Med} \mathrm{J}$ 1963; 2:216-9.

4 Read NW, Harford WV, Schmulen AC et al. A clinical study of patients with faecal incontinence and diarrhea. Gastroenterology 1979; 76:747-56.

5 Schuster MM, Hendrix TR, Mendeloff AI. The internal sphincter response: manometric studies on its normal physiology, neural pathways and alteration in bowel disorders. J Clin Invest 1963; 42:196-207.

6 Parks AC, Porter NH, Melzak J. Experimental study of the reflex mechanism controlling the muscles of the rectal floor. Dis Colon Rectum 1962; 5:407-14.

7 Kerremans R. Electrical activity and motility of the internal anal sphincter. Acta Gastroenterol Belg 1968; 31:465-82.

8 Scharli AF, Keisewetter WB. Defaecation and continence: some new concepts. Dis Colon Rectum 1970; 13:81-107. 